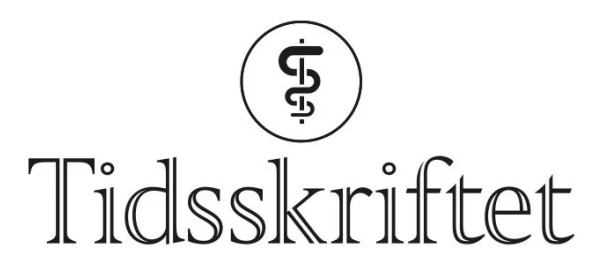

DEN NORSKE LEGEFORENING

\title{
Inflammatorisk multisystemsyndrom ved covid-19
}

SPRÅKSPALTEN

\section{PETTER GJERSVIK}

petter.gjersvik@medisin.uio.no

Petter Gjersvik er medisinsk redaktør i Tidsskriftet, redaktør for Språkspalten og professor ved Institutt for klinisk medisin ved Universitetet i Oslo.

\section{ASTRID ELISABETH ROJAHN}

Astrid Elisabeth Rojahn er spesialist i barnesykdommer og overlege ved Barne- og ungdomsklinikken ved Oslo universitetssykehus.

\section{BERIT FLAT $\varnothing$}

Berit Flatø er spesialist i revmatologi med særlig interesse for inflammatorisk sykdom hos barn, overlege ved Seksjon for revmatologi ved Oslo universitetssykehus og professor ved Institutt for klinisk medisin ved Universitetet i Oslo.

Multisystem inflammatory syndrome in children bør på norsk kalles inflammatorisk multisystemsyndrom hos barn. 


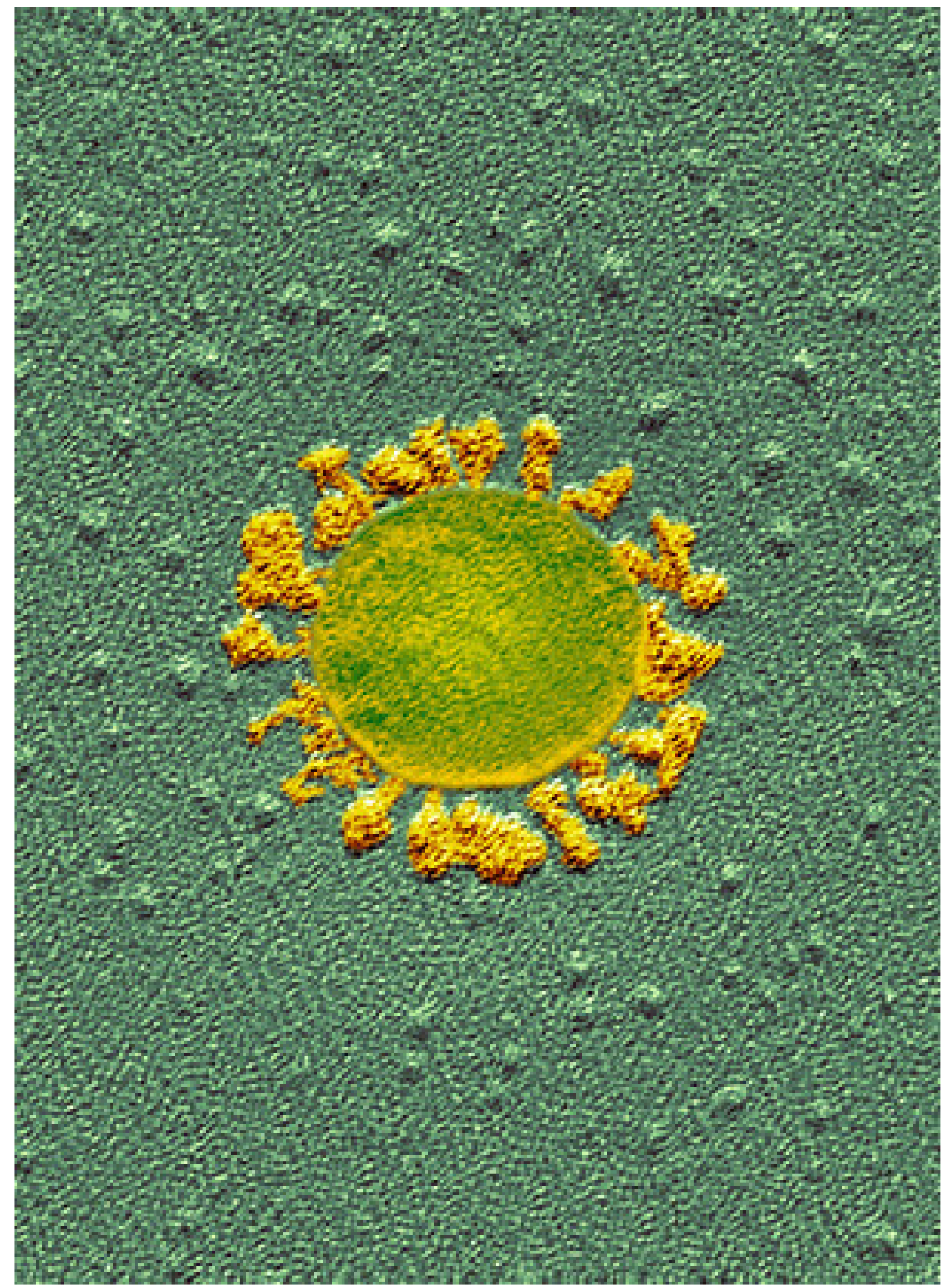

Farget transmisjonselektronmikroskopbilde av koronaviruset SARS-CoV-2. Illustrasjon:

Science Photo Library / NTB

Barn og unge som blir smittet med koronaviruset SARS-CoV-2, kan bli rammet av en immunmediert senreaksjon med høy feber, gastrointestinale symptomer og kardiogent sjokk (11). Denne sjeldne og alvorlige tilstanden omtales på engelsk som multisystem inflammatory syndrome in children ( $\underline{2})$, forkortet MIS-C. (Hos voksne brukes forkortelsen MISA, der A-en står for adults.) Tilstanden er også omtalt som pediatric inflammatory multisystem syndrome temporally associated with SARS-CoV-2, forkortet PIMS-TS (3).

Blant norske barneleger er nok tilstanden mest kjent som MIS-C. I tre artikler i Tidsskriftet har forfatterne, bl.a. to av oss (AER og BF), på norsk valgt betegnelsen multiorgan inflammatorisk syndrom, altså med multiorgan fremfor multisystem $(\mathbf{1}, 4,5)$. Det samme har Barnelegeforeningen gjort i sin pediatriveileder (므). Valget mellom ordene multiorgan og multisystem kan være en smakssak, men to forhold taler for multisystem: at tilstanden ikke 
bare affiserer organer, og at ordet multisystem brukes oftere i internasjonal faglitteratur enn multiorgan. Både Centers for Disease Control and Prevention (CDC) i USA og Verdens helseorganisasjon bruker betegnelsen multisystem inflammatory syndrome in children $(7, \underline{7})$.

Saken har også en annen språklig side, nemlig at verken multisystem eller multiorgan kan brukes som et frittstående adjektiv på norsk. Løsningen er egentlig ganske enkel: Bytt om på rekkefølgen av ordene, slik at det blir inflammatorisk multisystemsyndrom. En slik løsning er ikke til hinder for at barneleger seg imellom kan bruke forkortelsen MIS-C. Men utenfor eget fagmiljø bør de helst omtale tilstanden på en måte som bedre forklarer hva det dreier seg om (9).

\section{LITTERATUR}

1. Hu Y, Rojahn AE, Flatø B. Multiorgan inflammatorisk syndrom hos barn og ungdom etter SARSCoV-2-infeksjon. Tidsskr Nor Legeforen 2021; 141. doi: 10.4045/tidsskr.20.1040. [PubMed][CrossRef]

2. Son MBF, Murray N, Friedman K et al. Multisystem inflammatory syndrome in children - initial therapy and outcomes. N Engl J Med 2021; 385: 23-34. [PubMed][CrossRef]

3. Whittaker E, Bamford A, Kenny J et al. Clinical Characteristics of 58 Children With a Pediatric Inflammatory Multisystem Syndrome Temporally Associated With SARS-CoV-2. JAMA 2020;324: 25969. [PubMed][CrossRef]

4. Rojahn AE, Gammelsrud KW, Brunvand LI et al. Multiorgan inflammatorisk syndrom assosiert med sars-CoV-2 hos et barn. Tidsskr Nor Legeforen 2020; 140. doi: 10.4045/tidsskr.20.0485. [PubMed] [CrossRef]

5. Størdal K. Covid-19: Barn er ikke små voksne. Tidsskr Nor Legeforen 2021; 141. doi: 10.4045/tidsskr.21.0656. [PubMed][CrossRef]

6. Norsk barnelegeforening. Retningslinjer. Multiorgan inflammatorisk syndrom assosiert med Covid-19 (MIS-C). https://www.helsebiblioteket.no/pediatriveiledere? menuitemkeylev1 $=5962 \&$ menuitemkeylev2 $=59668 k e y=271455$ Lest 27.9.2021.

7. Centers for Disease Control and Prevention. Information for health care providers om multisystem inflammatory syndrome in children (MIS-C). https://www.cdc.gov/mis/mis-c/hcp/index.html? CDC_AA_refVal=https\%3A\%2F\%2Fwww.cdc.gov\%2Fmis\%2Fhcp\%2Findex.html Lest 27.9.2021.

8. World Health Organization. Clinical management of COVID-19 patients: living guidance, 25 January 2021. https://app.magicapp.org/\#/guideline/j1WBYn Lest 29.9.2021.

9. Gjersvik P. Forkortelser skaper avstand. Tidsskr Nor Legeforen 2021; 141. doi:10.4045/tidsskr.21.0636. [PubMed][CrossRef]

Publisert: 22. november 2021. Tidsskr Nor Legeforen. DOI: 10.4045/tidsskr.21.0683

(C) Tidsskrift for Den norske legeforening 2023. Lastet ned fra tidsskriftet.no 26. april 2023. 